\title{
DIFFERENCES IN SELENIUM UPTAKE AND TRANSPORT, AND RELATED GENE EXPRESSION IN THREE BRASSICA VEGETABLES
}

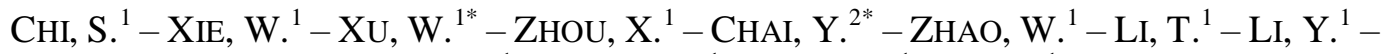 \\ ZHANG, C. ${ }^{1}-$ YANG, M. ${ }^{1}-$ FENG, D. ${ }^{1}-$ HE, Z. ${ }^{1}$ \\ ${ }^{I}$ College of Resources and Environmental Sciences, Southwest University \\ 400715 Chongqing, P. R. China \\ ${ }^{2}$ College of Agronomy and Biotechnology, Southwest University \\ 400715 Chongqing, P. R. China \\ *Corresponding authors \\ e-mail:xuwei_hong@163.com(W.Xu); chaiyourong1@163.com (Y. Chai) \\ (Received $7^{\text {th }}$ Feb 2018; accepted $3^{\text {rd }}$ May 2018)
}

\begin{abstract}
Selenium (Se) is an essential micronutrient for humans, animals and plant growth. The consumption of plant products containing a high Se concentration, is the most efficient and safe way of Se supplementation. Selenium concentrations in plants vary depending on exogenous selenium levels, plant species and variety. In the recent pot experiment, the effects of exogenous selenium $(0,0.5,1.0,2.5$ and $5 \mathrm{mg} \cdot \mathrm{kg}^{-1}$ ) on the selenium uptake and transport of three Brassica vegetables (Brassica rapa ssp. chinensis L., Brassica rapa ssp. pekinensis L. and Brassica oleracea var. capitata L.) were studied. The expression levels of selenium metabolism related genes families, such as APS, APR, SAT, SMT, CysD and MMT, were also detected using qRT-PCR assays. The results showed that selenium concentration in leaves, stems and roots of the three Brassica vegetables increased with the increase of soil selenium level. The selenium concentration in the leaves of the three Brassica vegetables was the highest at selenium level of $5 \mathrm{mg} \cdot \mathrm{kg}^{-1}$. Leaf selenium concentration of Brassica rapa ssp. chinensis L. was significantly 1.393.02 times higher than that of the other two vegetables. Under the same selenium treatment, selenium concentration, selenium accumulation coefficient and transport coefficient of edible parts of Brassica vegetables were the highest in Brassica rapa ssp. chinensis L. and the lowest in Brassica oleracea var. capitata $\mathrm{L}$. At soil selenium level of $5 \mathrm{mg} \cdot \mathrm{kg}^{-1}$, the expression levels of SAT, SMT and MMT in leaves of Brassica rapa ssp. chinensis L. and the expression levels of SAT, APS, SMT, APR and MMT in leaves of Brassica pekinensis L. significantly increased. Brassica rapa ssp. chinensis L. had the best selenium enrichment effect among the three Brassica vegetables.
\end{abstract}

Keywords: selenium, Brassica, bioconcentration factor, qRT-PCR, selenium metabolism related genes

Abbreviations: Se - selenium, APS - ATP sulfurylase, APR - APS reductase, SAT - Serine acetyltransferase, CysD - Cysteine desulfurase, MMT - S-adenosyl-L-Met:L-Met S-methyltransferase, SMT - selenocysteine methyltransferase, MeSeCys - methylselenocysteine, SeMet - Selenomethionine, $\mathrm{OAS}$ - O-acetylserine, BCF - bioconcentration factor, TF - translocation factor, SeMM - methyl-

Semethionine, SMM - thiomethyl methionine

\section{Introduction}

Selenium (Se), a vital trace element for humans, is important for preventing disease, improving health, and preventing aging and has been considered a life-protecting agent (Gupta et al., 2016). Most soils of the world has a selenium content of $0.01-2.0 \mathrm{mg} \cdot \mathrm{kg}^{-1}$, with an average content of $0.4 \mathrm{mg} \cdot \mathrm{kg}^{-1}$. In selenium-deficient soil, Se content is less than $0.15 \mathrm{mg} \cdot \mathrm{kg}^{-1}$. The world's selenium-deficient population reaches 1.5 billion (Zhu et al., 2009). About $72 \%$ of China's land area has varying degrees of selenium deficiency (Zhou et al., 2016). Selenium content of less than $0.05 \mathrm{mg} \cdot \mathrm{kg}^{-1}$ in human 
foods results in selenium deficiency, but greater than $5 \mathrm{mg} \cdot \mathrm{kg}^{-1}$ can be toxic (Wen, 2006). Inorganic selenium supplementation not only has the problem of low uptake and conversion rate, but also will adversely affect human health because of the narrow safe dose range of selenium (Keskinen et al., 2010; Zhao et al., 2017). Bio-selenium is the safest and most effective way to supplement human selenium (Ellis and Salt, 2003; Song et al., 2017). By absorbing and enriching exogenous selenium and converting it to safe and effective bioorganic selenium, crops improve human or animal selenium nutrition in low and selenium-deficient areas (Zhang et al., 2014; Li et al., 2015; Liu et al., 2017).

Selenium levels in plants vary depending on exogenous selenium levels, plant species and variety (Longchamp et al., 2015; Bañuelos et al., 2016). Under the same soil selenium level, the selenium concentrations in fruits of different tomato varieties were ranked as Luobeiqi > KT30 > Defumm-8 (Zhao et al., 2017). The selenium concentration in shoot, stem and root of Brassica rapa Linn L. was higher than that of Brassica tumida Tsenet Lee L. at the same soil selenium level (Xie, 2016). However, there are also reports to the contrary. Yawata et al. (2010) conducted a study on three cruciferous crops [Indian mustard (Brassica juncea), nozawana (Brassica rapa var. hakabura) and komatsuna (Brassica rapa var. peruviridis)] and found that there was no significant difference in selenium concentration among the three crops. However, due to its rapid growth and larger biomass, komatsuna has higher selenium accumulation.

ATP sulfurylase (APS) exerts a rate limiting effect on selenate reduction and selenium assimilation (Matich, et al., 2012; Zhang, 2014). Overexpression of APS in transgenic plants promoted APSe separation into AMP and selenite and increased selenium accumulation (Xie, 2016; Zhao et al., 2017). APR (APS reductase) is the APS reductase gene. Methylation is the major metabolic pathway for selenium in plants. After selenomethionine (SeMet) production, selenium is converted to methylselenocysteine (MeSeCys) by the methylation pathway under the action of selenocysteine methyltransferase (SMT) (Song et al., 2017). SMT activity is closely linked to the high accumulation of selenium in eight species of Astragalus with different selenium enrichment ability (Fang et al., 2017; Schiavon and Pilon-Smits, 2017). McKenzie et al. (2009) reported that $200 \mu \mathrm{M}$ selenium application resulted in an overexpression of SMT transgene in crops, which increased selenium accumulation in crops by 2-4 times, made MeSeCys content reach $20 \%$ of the total selenium, with MeSeCys directly converted to methyl second-generation selenium. In addition, CysD (Cysteine desulfurase), MMT (S-adenosyl-L-Met:L-Met S-methyltransferase) and SAT (Serine acetyltransferase) were also found to be the main genes for plant metabolism and selenium accumulation. Co-expression of SAT and SMT promoted the increase of OAS (O-acetylserine), which in turn promoted the expression of sulfur transporter as well as plant uptake and accumulation of selenium (Çakır et al., 2012; Song et al., 2017).

Brassica has the strongest selenium enrichment ability (Wiesner-Reinhold et al., 2017). At present, there are many reports on selenium-enriched crops at home and abroad (Matich, et al., 2012; Zhao et al., 2017). However, there are few reports of Se enrichment difference and Se related gene expression in Brassica vegetables (Xie, 2016). In this experiment, Brassica rapa ssp. chinensis L. (pakchoi), Brassica rapa ssp. pekinensis L. (Chinese cabbage) and Brassica oleracea var. capitata L. (cabbage) were used as materials to compare the differences in selenium uptake, selenium transformation and transport among the three Brassica vegetables. Also, selenium metabolism related gene expression of the three Brassica vegetable s was tested. 


\section{Materials and methods}

\section{Plant material, soil and Se treatments}

The seeds of Brassica rapa ssp. chinensis L., Brassica rapa ssp. pekinensis L. and Brassica oleracea var. capitata L. were purchased from Xiema farmer's market in Beibei district, Chongqing, China. The experimental soil was taken from Jiulongpo District of Chongqing, China. The soil $\mathrm{pH}$ was 6.70 , soil organic matter was $9.08 \mathrm{~g} \cdot \mathrm{kg}^{-1}$, soil total nitrogen was $0.64 \mathrm{~g} \cdot \mathrm{kg}^{-1}$, soil available nitrogen was $72.77 \mathrm{mg} \cdot \mathrm{kg}^{-1}$, soil available phosphorus was $54.81 \mathrm{mg} \cdot \mathrm{kg}^{-1}$, soil available potassium was $216.7 \mathrm{mg} \cdot \mathrm{kg}^{-1}$, soil cation exchange capacity was $30.3 \mathrm{cmol} \cdot \mathrm{kg}^{-1}$, soil total selenium was $0.42 \mathrm{mg} \cdot \mathrm{kg}^{-1}$ and soil available selenium was $0.029 \mathrm{mg} \cdot \mathrm{kg}^{-1}$.

Pot experiment was conducted at No. 1 glass greenhouse of College of Resources and Environment of Southwest University, Beibei District, Chongqing, China (106.4N, 29.8E), from November 4, 2014 to February 25, 2015. Five selenium levels (0, 0.5, 1.0, 2.5 and $5 \mathrm{mg} \cdot \mathrm{kg}^{-1}$ ) prepared from $\mathrm{Na}_{2} \mathrm{SeO}_{3}$ were set up. Considering the larger biomass of Brassica oleracea var. capitata L. than Brassica rapa ssp. chinensis L. and Brassica rapa ssp. pekinensis L., two plant $\cdot$ pot $^{-1}$ of Brassica oleracea var. capitata L., three plant pot $^{-1}$ of Brassica rapa ssp. chinensis L. and Brassica rapa ssp. pekinensis L. respectively were planted in black plastic basin $(25 \mathrm{~cm}$ in diameter and $17 \mathrm{~cm}$ in height), each basin was loaded with $5 \mathrm{~kg}$ of air-dried soil screened with $5 \mathrm{~mm}$ sieve. The total dosage of nitrogen fertilizer, phosphate fertilizer and potassium fertilizer was $180 \mathrm{mg} \cdot \mathrm{kg}^{-1}, 100 \mathrm{mg} \cdot \mathrm{kg}^{-1}$ and $150 \mathrm{mg} \cdot \mathrm{kg}^{-1}$, respectively. Ammonium nitrate, monopotassium phosphate and potassium sulphate were used as nitrogen, phosphate and potassium fertilizers, respectively. Each treatment was repeated 3 times and arranged randomly. During the cultivation period, pure water was used to maintain soil water content at $60 \%-80 \%$ of the maximum water holding capacity of the field. Considering the longer growth period of Brassica oleracea var. capitata L., Brassica oleracea var. capitata L. was harvested after 85 days, and Brassica rapa ssp. chinensis L. and Brassica rapa ssp. pekinensis L. were harvested after 65 days. Edible parts of vegetables were taken, quick-frozen by liquid nitrogen and placed in $-80^{\circ} \mathrm{C}$ refrigerator for later RNA extraction.

\section{Analysis of soil physicochemical properties}

The soil $\mathrm{pH}$ was ascertained in 1:5 (soil: water), and available phosphorus, available potassium and total nitrogen in soil was determined in term of a previously report (Rayment and Higginson, 1992). The soil cation exchange capacity and soil organic matter content was determined on the basis of a previously published method (McCleod, 1975).

\section{Analysis of Se concentrations in soil and plants}

Soil and plant samples were ground and digested at $170^{\circ} \mathrm{C}$ using $10 \mathrm{~mL}$ of acid mixture $(8 \mathrm{~mL}$ of ultrapure nitric acid and $2 \mathrm{~mL}$ of perchloric acid) (Kyodan et al., 1988). The acid mixture was heated until white smoke appeared; further, $10 \mathrm{~mL}$ of 6 $\mathrm{mol} \cdot \mathrm{L}^{-1}$ hydrochloric acid was added, and the mixture was heated until the white smoke reappeared (Kyodan et al., 1988). The residual sample was then diluted in $25 \mathrm{~mL}$ of ultrapure water (Kyodan et al., 1988). The concentration of Se in the solution was 
analyzed using hydride generation atomic fluorescence spectrometry (PF6.3, Beijing Purkinje General Instrument Co. Ltd., China).

\section{Detection of gene expression}

RNA was extracted from edible part of the sample stored in the refrigerator at $-80{ }^{\circ} \mathrm{C}$. The specific procedure followed the operation manual of the RNA extraction kit purchased from Tiangen Biotechnology Company (Beijing, China). Purification of total RNA, RNA detection, synthesis of reverse transcription cDNA, primer design and synthesis, PCR amplification of cDNA and real-time quantitative PCR were done according to Zhao et al. (2017) method.

\section{The statistical analysis}

Data were analyzed by one-way analysis of univariate ANOVA and followed by Duncan's multiple comparison tests using SPSS version 21.0 (IBM Corp., Armonk, NY, USA). The variables analyzed separately were Se concentration, bioconcentration factor (BCF) and translocation factor (TF) of Se in three Brassica vegetables. The BCF refers to the ratio of the Se concentration in tissues to the exogenous Se. TF is the ratio of Se concentration in shoots to that in roots (Renkema et al., 2011). The level of significance was 0.05 .

\section{Results}

\section{Selenium concentration}

As can be seen from Figure 1, the selenium concentration in leaves, stems and roots of the three Brassica vegetables increased with the increase of soil selenium level. The selenium concentration in leaves, stems and roots of the three Brassica vegetables was the highest at the maximum level of soil selenium $\left(5 \mathrm{mg} \cdot \mathrm{kg}^{-1}\right)$. At this time, leaf selenium concentration of Brassica rapa ssp. chinensis L. was significantly higher than that of the other Brassica vegetables by 1.39-3.02 times. Under the same selenium level, selenium concentration in stem and root of Brassica oleracea var. capitata L. was the lowest among the three Brassica vegetables.

\section{Selenium transport ability}

In order to better compare the differences in selenium uptake, transport and accumulation among the main Brassica vegetables, bioconcentration factor (BCF) and transport factor (TF) were introduced in this study to characterize the enrichment and transport of selenium in different Brassica vegetables. A higher BCF value indicates stronger selenium enrichment ability. A higher TF value suggests stronger ability of plants to transport selenium absorbed by the roots to shoot.

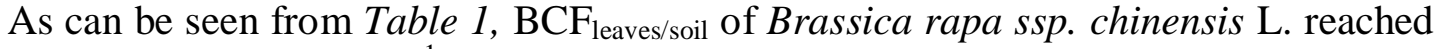
the maximum at $0.5 \mathrm{mg} \cdot \mathrm{kg}^{-1}$ selenium, and decreased with the increase of soil selenium level. Selenium treatment had no significant effect on the $\mathrm{BCF}_{\text {leaves/soil }}$ of Brassica rapa ssp. pekinensis L. and Brassica oleracea var. capitata L. With the increase of soil selenium levels, $\mathrm{BCF}_{\text {stem/soil }}$ of three Brassica vegetables firstly decreased and then increased, reaching the highest at $0.5 \mathrm{mg} \cdot \mathrm{kg}^{-1}$ selenium. 

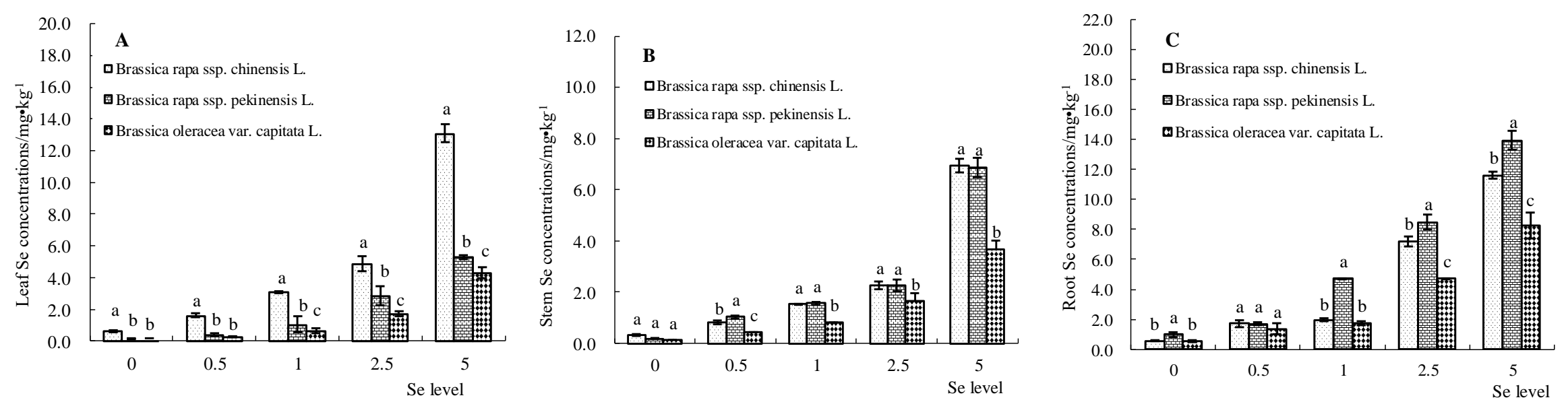

Figure 1. Effects of different concentrations of selenium on the selenium concentrations of leaf, stem and root in different Brassica vegetables. Different letters $(a, b, c)$ indicate significant difference at $P \leq 0.05$ among different species.

Table 1. Bioconcentration factor $(B C F)$ and translocation factor $(T F)$ of Se in different Brassica vegetables

\begin{tabular}{|c|c|c|c|c|c|c|c|c|c|c|c|c|}
\hline \multirow[b]{2}{*}{ 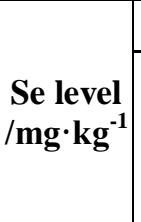 } & \multicolumn{3}{|c|}{$\mathrm{BCF}_{\text {leaevs/soil }}$} & \multicolumn{3}{|c|}{$\mathrm{BCF}_{\text {stem/soil }}$} & \multicolumn{3}{|c|}{$\mathrm{BCF}_{\text {root/soil }}$} & \multicolumn{3}{|c|}{ TF } \\
\hline & $\begin{array}{c}\text { Brassica } \\
\text { rapa ssp. } \\
\text { chinensis } \\
\text { L. }\end{array}$ & \begin{tabular}{|c|} 
Brassica \\
rapa ssp. \\
pekinensis \\
L. \\
\end{tabular} & $\begin{array}{c}\text { Brassica } \\
\text { oleracea } \\
\text { var. } \\
\text { capitata } \mathrm{L} .\end{array}$ & $\begin{array}{c}\text { Brassica } \\
\text { rapa ssp. } \\
\text { chinensis } \\
\text { L. } \\
\end{array}$ & $\begin{array}{l}\text { Brassica } \\
\text { rapa ssp. } \\
\text { pekinensis } \\
\text { L. } \\
\end{array}$ & $\begin{array}{c}\text { Brassica } \\
\text { oleracea } \\
\text { var. } \\
\text { capitata } \mathbf{L} .\end{array}$ & $\begin{array}{l}\text { Brassica } \\
\text { rapa ssp. } \\
\text { chinensis } \\
\text { L. }\end{array}$ & $\begin{array}{c}\text { Brassica } \\
\text { rapa ssp. } \\
\text { pekinensis } \\
\text { L. }\end{array}$ & $\begin{array}{c}\text { Brassica } \\
\text { oleracea } \\
\text { var. } \\
\text { capitata } \mathrm{L} . \\
\end{array}$ & $\begin{array}{c}\text { Brassica } \\
\text { rapa ssp. } \\
\text { chinensis } \\
\text { L. } \\
\end{array}$ & \begin{tabular}{|c|} 
Brassica \\
rapa ssp. \\
pekinensis \\
L. \\
\end{tabular} & $\begin{array}{c}\text { Brassica } \\
\text { oleracea } \\
\text { var. } \\
\text { capitata } \mathrm{L} .\end{array}$ \\
\hline 0 & - & - & - & - & - & - & - & - & - & - & - & - \\
\hline 0.5 & $3.24 \pm 0.24 \mathrm{a}$ & $0.80 \pm 0.95 b$ & $0.50 \pm 0.67 \mathrm{c}$ & $1.66 \pm 0.16 \mathrm{~b}$ & $2.06 \pm 0.14 \mathrm{a}$ & $0.89 \pm 0.03 \mathrm{c}$ & $3.46 \pm 0.46 \mathrm{a}$ & $3.39 \pm 1.0 \mathrm{a}$ & $2.71 \pm 0.70 \mathrm{~b}$ & $1.43 \pm 0.30 \mathrm{a}$ & $0.93 \pm 0.52 b$ & $0.56 \pm 0.38 \mathrm{c}$ \\
\hline 1.0 & $3.09 \pm 0.06 \mathrm{a}$ & $1.05 \pm 0.50 \mathrm{~b}$ & $0.69 \pm 0.14 \mathrm{c}$ & $1.52 \pm 0.02 \mathrm{a}$ & $1.56 \pm 0.06 \mathrm{a}$ & $0.66 \pm 0.12 b$ & $1.98 \pm 0.08 b$ & $4.72 \pm 0.03 \mathrm{a}$ & $1.89 \pm 0.01 \mathrm{~b}$ & $2.34 \pm 0.10 \mathrm{a}$ & $0.55 \pm 0.09 c$ & $0.72 \pm 0.01 \mathrm{~b}$ \\
\hline 2.5 & $1.95 \pm 0.18 \mathrm{a}$ & $1.15 \pm 0.24 b$ & $0.65 \pm 0.16 c$ & $0.91 \pm 0.07 \mathrm{a}$ & $0.90 \pm 0.09 \mathrm{a}$ & $0.84 \pm 0.05 \mathrm{a}$ & $2.88 \pm 0.33 b$ & $3.40 \pm 0.19 \mathrm{a}$ & $1.73 \pm 0.65 \mathrm{c}$ & $0.99 \pm 0.02 \mathrm{a}$ & $0.60 \pm 0.06 \mathrm{~b}$ & $0.94 \pm 0.42 \mathrm{a}$ \\
\hline 5.0 & $2.62 \pm 0.11 \mathrm{a}$ & $1.06 \pm 0.03 \mathrm{~b}$ & $0.86 \pm 0.01 \mathrm{c}$ & $1.39 \pm 0.01 \mathrm{a}$ & $1.37 \pm 0.07 \mathrm{a}$ & $0.74 \pm 0.07 b$ & $2.32 \pm 0.31 \mathrm{~b}$ & $2.79 \pm 0.61 \mathrm{a}$ & $1.65 \pm 0.25 \mathrm{c}$ & $1.74 \pm 0.27 \mathrm{a}$ & $0.89 \pm 0.16 b$ & $0.99 \pm 0.20 \mathrm{~b}$ \\
\hline
\end{tabular}

Different letters $(\mathrm{a}, \mathrm{b}, \mathrm{c})$ indicate significant difference at $P \leq 0.05$ among different species. "_" indicates selenium concentrations below the detection limit $\left(0.005 \mathrm{mg} \cdot \mathrm{kg}^{-1}\right)$. The results listed are mean \pm standard deviation. 
With the increase of soil selenium level, $\mathrm{BCF}_{\text {root/soil }}$ of the three vegetables decreased first, reaching the lowest value at $1 \mathrm{mg} \cdot \mathrm{kg}^{-1}$ soil selenium level, and then increased again, but still lower than that of non-selenium treatment. $\mathrm{BCF}_{\text {root/soil }}$ of Brassica oleracea var. capitata L. was significantly reduced at high levels of selenium $\left(5 \mathrm{mg} \cdot \mathrm{kg}^{-}\right.$ ${ }^{1}$ ), which was $39.01 \%$ lower than in the case of $0.5 \mathrm{mg} \cdot \mathrm{kg}^{-1}$ selenium level. Selenium transport coefficient of Brassica rapa ssp. chinensis L. and Brassica rapa ssp. pekinensis L. increased with the increase in exogenous selenium, indicating that greater soil selenium levels enhanced the ability of the two Brassica vegetables to transport selenium from the root to the shoot. On the contrary, Brassica oleracea var. capitata L. showed the opposite trend. For selenium transport coefficient (TF), that of Brassica rapa ssp. chinensis L. > Brassica rapa ssp. pekinensis L. $\approx$ Brassica oleracea var. capitata L., indicating that among the three tested Brassica vegetables, Brassica rapa ssp. chinensis L. has the strongest ability to transport selenium to shoot. In comparison of selenium enrichment factor of edible parts among the three Brassica vegetables, Brassica rapa ssp. chinensis L. ranked the top, while Brassica oleracea var. capitata L. was at the bottom.

\section{Expression of selenium metabolism related gene}

As can be seen from Figure 2, at soil selenium level $\leq 0.5 \mathrm{mg} \cdot \mathrm{kg}^{-1}$, the SAT expression level was not significant in the leaves of Brassica rapa ssp. chinensis L. When the soil selenium level increased to $1 \mathrm{mg} \cdot \mathrm{kg}^{-1}$, SAT expression level decreased drastically, reaching the lowest at $2.5 \mathrm{mg} \cdot \mathrm{kg}^{-1}$ selenium, but significantly increased at $5 \mathrm{mg} \cdot \mathrm{kg}^{-1}$ soil selenium level.
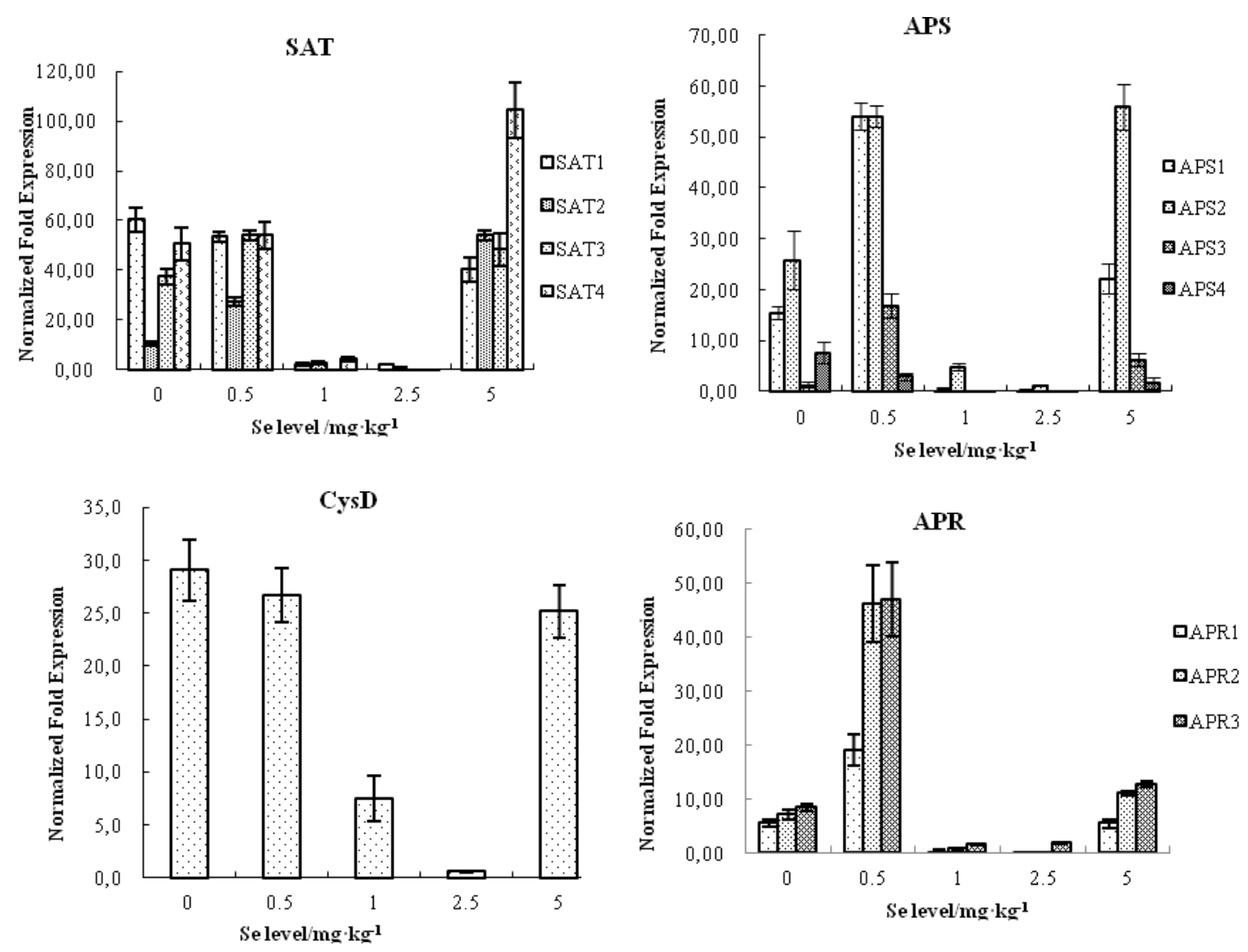

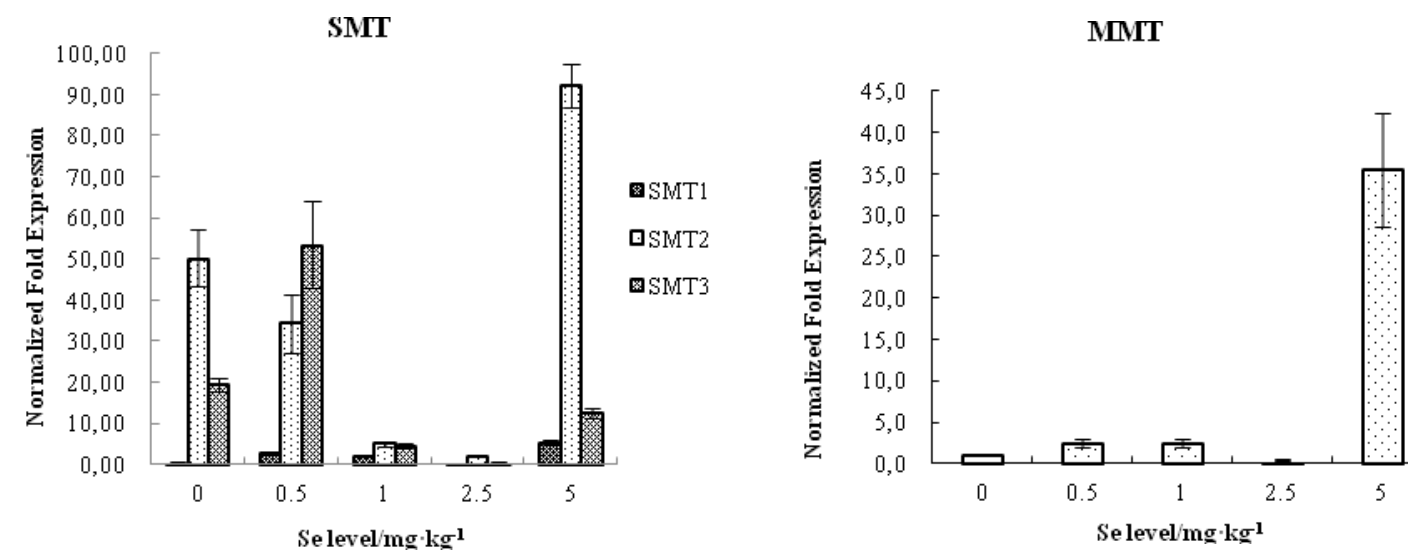

Figure 2. Real-time PCR analysis of Se metabolism associated genes in leaf of Brassica rapa ssp. chinensis $L$.

The expression level of SAT4 gene was the highest in SAT genes family of Brassica rapa ssp. chinensis $\mathrm{L}$. at the same selenium level. Exogenous selenium inhibited the expression of APS4. At $0.5 \mathrm{mg} \cdot \mathrm{kg}^{-1}$ soil selenium level, the expression levels of APS1, APS2 and APS3 increased by 1.10-12.20 times compared with those of non-selenium treatment. At soil selenium level $\geq 1 \mathrm{mg} \cdot \mathrm{kg}^{-1}$, expression level of APS was in order of APS2 > APS1 > APS3 > APS4 under the same selenium treatment. CysD gene expression level decreased first with the increase of soil selenium level, reaching the lowest level at $2.5 \mathrm{mg} \cdot \mathrm{kg}^{-1}$ selenium, and then increased. However, CysD expression level in all selenium treatments was lower than that of non-selenium treatment. With the increase of soil selenium level, APR gene expression level first increased, reaching the highest level at $0.5 \mathrm{mg} \cdot \mathrm{kg}^{-1}$ selenium, and then decreased. Under the same selenium treatment, APR expression level was ranked as APR3 > APR2 > APR1. With the change of soil selenium level, SMT2 expression level was the lowest at $2.5 \mathrm{mg} \cdot \mathrm{kg}^{-1}$, reaching the peak at $5 \mathrm{mg} \cdot \mathrm{kg}^{-1}$. SMT2 expression level was 1.84 times that of nonselenium treatment. Variation trend of SMT1 and SMT3 gene expression was consistent with that of APR. At soil selenium level $\leq 2.5 \mathrm{mg} \cdot \mathrm{kg}^{-1}$, there was no significant difference in MMT gene expression level. When selenium level increased to $5 \mathrm{mg} \cdot \mathrm{kg}^{-1}$, MMT expression level significantly increased, which was 33.42 times that of nonselenium treatment. Except MMT, selenium metabolism-related gene expression in leaves of Brassica rapa ssp. chinensis L. was inhibited at $1 \mathrm{mg} \cdot \mathrm{kg}^{-1}$ and $2.5 \mathrm{mg} \cdot \mathrm{kg}^{-1}$ selenium.

As can be seen from Figure 3, at soil selenium level $\leq 2.5 \mathrm{mg} \cdot \mathrm{kg}^{-1}$, expression levels of SAT, APS, SMT and APR in leaves of Brassica rapa ssp. pekinensis L. were low, but increased significantly at $5 \mathrm{mg} \cdot \mathrm{kg}^{-1}$ selenium level. The expression level of SAT2, SAT4, APS2, SMT2 and APR2 was found the highest in the SAT, APS, SMT and APR genes family respectively. Exogenous selenium inhibited CysD expression level in leaves of Brassica rapa ssp. pekinensis L. MMT expression level first decreased with the increase of soil selenium level, reaching the lowest at $1 \mathrm{mg} \cdot \mathrm{kg}^{-1}$ selenium level, and then increased, reaching the highest level at $5 \mathrm{mg} \cdot \mathrm{kg}^{-1}$ soil selenium level.

As can be seen from Figure 4, except that APR1 expression in leaves of Brassica oleracea var. capitata L. was inhibited by exogenous selenium, the expression of other genes in leaves of Brassica oleracea var. capitata L. increased and then decreased with 
the increase of soil selenium levels, reaching the highest at $0.5 \mathrm{mg} \cdot \mathrm{kg}^{-1}$ selenium level. The APS expression in wild cabbage leaves was the highest among all the six genes, and APS4 expression level in leaves of Brassica oleracea var. capitata L. was up to 994.62 at $0.5 \mathrm{mg} \cdot \mathrm{kg}^{-1}$ selenium.

The qRT-PCR assays of all Se metabolism related genes showed that the expression levels of detected genes in Brassica oleracea var. capitata L. were more severely regulated than that in other two vegetables at the same soil Se level. Moreover, the expression levels of all detected genes in Brassica oleracea var. capitata L. was much higher than that in other two vegetables even at soil selenium level $\leq 2.5 \mathrm{mg} \cdot \mathrm{kg}^{-1}$ (Figs. 2, 3 and 4). It indicated that Brassica oleracea var. capitata L. might be more tolerant to exogenous Se and may has more complicate Se metabolism processes than Brassica rapa ssp. chinensis L. and Brassica rapa ssp. pekinensis L.
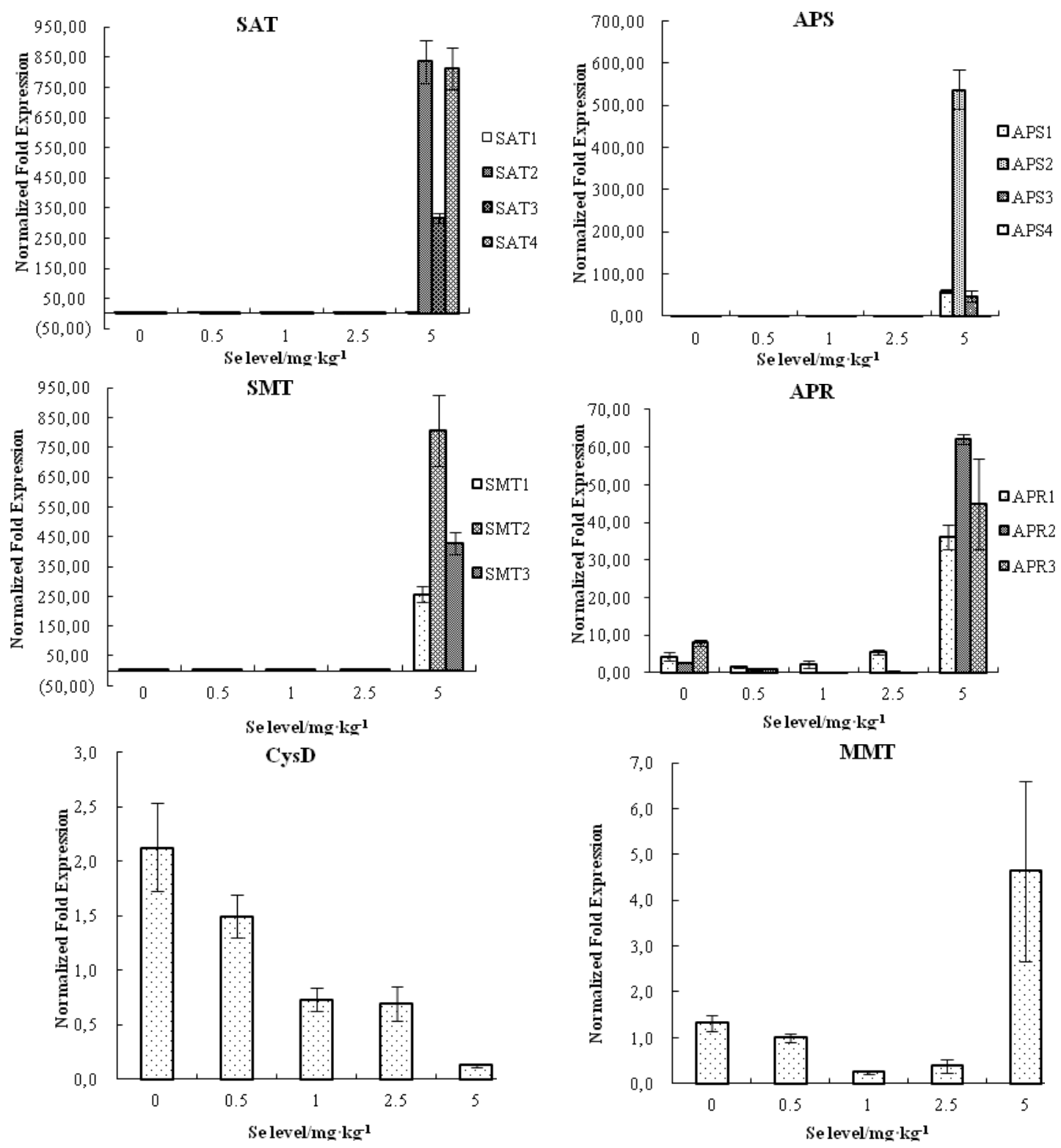

Figure 3. Real-time PCR analysis of Se metabolism associated genes in leaf of Brassica rapa ssp. pekinensis $L$. 

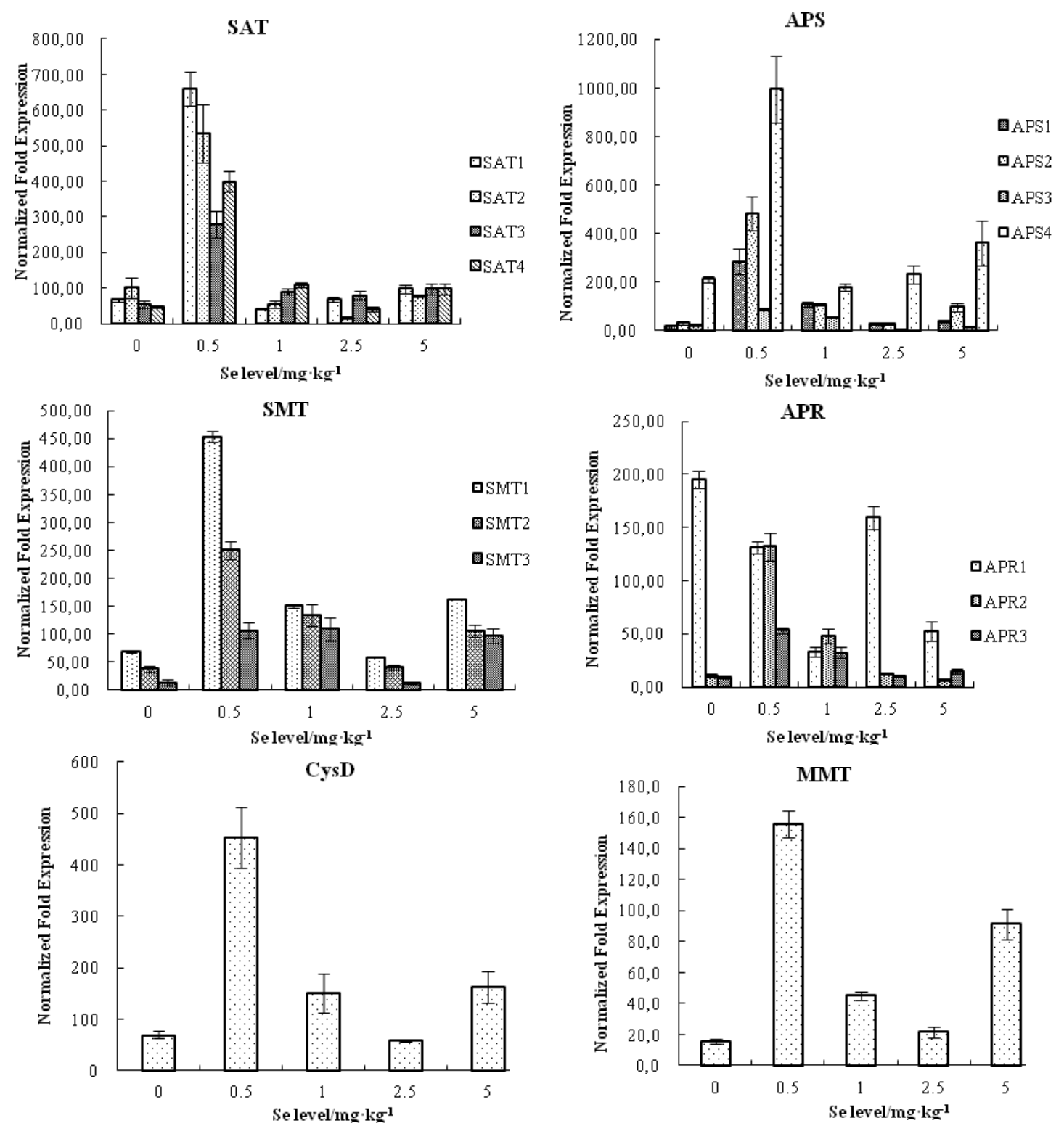

Figure 4. Real-time PCR analysis of Se metabolism associated genes in leaf of Brassica oleracea var. capitata $L$.

\section{Discussion}

In pot experiment, the accumulation of selenium in Brassica vegetables increased with the increase of soil selenium level, but selenium was extravagantly absorbed in Brassica vegetables at $5 \mathrm{mg} \cdot \mathrm{kg}^{-1}$ selenium. This result was similar to that reported by Zhao et al. (2017). The uptake of selenium by plants varies according to the plant species (Šindelářová et al., 2015). For the three Brassica vegetables, Brassica rapa ssp. chinensis L. had the highest selenium uptake, while Brassica oleracea var. capitata L. had the lowest, probably because selenium action sites differ for different vegetables. To discover the specific reasons, in depth study is needed of the expression levels of selenium metabolism related genes. 
Much of the selenite absorbed remains in the roots, with only a small fraction transported to the stems and leaves (Wiesner-Reinhold et al., 2017). In this experiment, $\mathrm{BCF}_{\text {root/soil }}>\mathrm{BCF}_{\text {leaf/soil }}$ of Brassica rapa ssp. pekinensis L. and Brassica oleracea var. capitata L. suggested that the selenium absorbed by the two Brassica vegetables mainly accumulated in the roots. $\mathrm{BCF}_{\text {stem/soil }}<\mathrm{BCF}_{\text {root/soil }}<\mathrm{BCF}_{\text {leaf/soil }}$ of Brassica rapa ssp. chinensis L. indicated that it was more able to transport selenium to shoots. Moreover, during selenium transportation in the body of Brassica rapa ssp. chinensis L., there was no hindrance in selenium transport from root to leaf. In comparison among the three Brassica vegetables, $\mathrm{BCF}_{\text {leaevs/soil }}, \mathrm{BCF}_{\text {stem/soil }}$ and transport coefficient $(\mathrm{TF})$ were the lowest in Brassica oleracea var. capitata L., indicating that it had relatively weak capacity of selenium uptake and selenium transport. In this experiment, selenium content, selenium enrichment coefficient and transport coefficient was the highest in Brassica rapa ssp. chinensis L. among the three Brassica vegetables, so Brassica rapa ssp. chinensis L. had the best selenium enrichment among the three Brassica vegetables.

Selenite has been found to be bioabsorbable by high-affinity proactive transport mechanism of ATP. Overexpression of ATP sulfurylase in transgenic plants accelerates this process and increases selenium tolerance and accumulation (Araie et al., 2008). Leduc et al. (2006) team over-expressed mustard ATP sulfurylase and SMT genes in Indian mustard at the same time, finding that mustard selenium content increased by 4-9 times. Terry et al. (2000) obtained transgenic plants that had increased selenium tolerance and enrichment by overexpression of seleno methyltransferase (SMT) in Arabidopsis and Indian mustard. In this experiment, ATP and APS expression levels of Brassica rapa ssp. chinensis L. and Brassica oleracea var. capitata L. increased significantly under selenium treatment. Meanwhile, exogenous selenium also increased SMT gene expression level, but high selenium level $\left(\leq 2.5 \mathrm{mg} \cdot \mathrm{kg}^{-1}\right)$ would downregulate transcription level of SMT gene mRNA in Brassica oleracea var. capitata L., showing that SMT could enhance the tolerance of vegetables to selenium under highselenium treatment, thus increasing the accumulation of selenium. SAT and CysD are two important enzymes involved in the synthesis and regulation of cysteine, and the two combine to form cysteine synthase (Çakır et al., 2012). In this experiment, SAT expression level in leaf of Brassica rapa ssp. pekinensis L. firstly increased and then decreased with the increase of soil selenium level. Exogenous selenium inhibited CysD expression in leaf of Brassica rapa ssp. pekinensis L., which may be due to the competitive effect of selenium and sulfur that caused inorganic sulfur hare to mix with cysteine, thus the transcription level of CysD gene mRNA was down-regulated. The expression levels of leaf genes SAT and CysD in the other two Brassica vegetables showed the same trend under the same treatment, probably due to the synergistic effect of the complexes formed by the two in plant cells (Liu et al., 2017). Methionine methyltransferase plays a key role in the production of volatile compounds in plants. SeMet and Met produce methyl-Semethionine (SeMM) and thiomethyl methionine (SMM) by homocysteine methyltransferase and methionine methyltransferase (MMT), and these compounds have toxic effects on non-selenium plants (Araie et al., 2008). In this experiment, the expression of MMT in leaves of Brassica rapa ssp. chinensis L. and Brassica rapa ssp. pekinensis L. was not significant at soil selenium level $\leq$ $2.5 \mathrm{mg} \cdot \mathrm{kg}^{-1}$, but significantly increased at soil selenium level of $5 \mathrm{mg} \cdot \mathrm{kg}^{-1}$. Under the same selenium level, the expression level of the same gene in different vegetables was significantly different, which may be related to the different transcriptional levels of mRNA. 


\section{Conclusion}

The selenium concentrations in leaves, stems and roots of the three Brassica vegetables increased with the increase of soil selenium level, and selenium concentration in leaves was the highest at soil selenium level of $5 \mathrm{mg} \cdot \mathrm{kg}^{-1}$. At $5 \mathrm{mg} \cdot \mathrm{kg}^{-1}$ selenium level, the expression levels of SAT, SMT and MMT in leaves of Brassica rapa ssp. chinensis L. and the expression levels of SAT, APS, SMT, APR and MMT in leaves of Brassica rapa ssp. pekinensis L. were significantly increased, while expression levels of SAT, APS, SMT, APR, MMT and CysD in leaves of Brassica oleracea var. capitata L. were significantly decreased. Under the same exogenous selenium level, the selenium concentration, selenium enrichment coefficient and transport coefficient of edible parts were highest in Brassica rapa ssp. chinensis L. and the lowest in Brassica oleracea var. capitata L. among the three Brassica vegetables. Brassica rapa ssp. chinensis L. had the best selenium enrichment effect among the three Brassica vegetables. However, the field application of selenium-enriched vegetables should be studied in the future.

Acknowledgements. This work was supported by Fund of China Agriculture Research System (CARS23), the National Science and Technology Pillar Program of China (No. 2007BAD87B10), the National Natural Science Foundation of China (No.31372141; 31672238), and the Ministry of Science and Technology of China (grant No. 2016YFD0100506).

\section{REFERENCES}

[1] Araie, H., Suzuki, I., Shiraiwa, Y. (2008): Identification and characterization of a selenoprotein, thioredoxin reductase, in a unicellular marine haptophyte alga Emiliania huxleyi. - J. Biol. Chem. 283: 35329-35336.

[2] Bañuelos, G. S., Arroyo, I. S., Dangi, S. R., Zambrano, M. C. (2016): Continued selenium biofortification of carrots and broccoli grown in soils once amended with seenriched S. pinnata. - Front. Plant Sci. 7: 1251-1262.

[3] Bao, S. D. (2000): Analysis methods of soil agro-chemistry. - China Agriculture Press, Beijing (in Chinese).

[4] Çakır, Ö., Turgut-Kara, N., Arı, Ş. (2012): Selenium Metabolism in Plants: Molecular Approaches. - In: Montanaro, G., Dichio, B. (eds.) Advances in Selected Plant Physiology Aspects, pp. 209-232. InTech Publications, Rijeka.

[5] Ellis, D. R., Salt, D. E. (2003): Plants, selenium and human health. - Curr. Opin. Plant Biol. 6: 273-279.

[6] Fang, Y., Chen, X., Luo, P., Pei, F., Kimatu, B. M., Liu, K., Du, M. J., Qiu, W. F., Hu, Q. H. (2017): The correlation between in vitro antioxidant activity and immunomodulatory activity of enzymatic hydrolysates from selenium-enriched rice protein. - J. Food Sci. 82: 517-522.

[7] Gupta, M., Gupta, S. (2016): An overview of selenium uptake, metabolism, and toxicity in plants. - Frontiers in Plant Science 7: 2074.

[8] Keskinen, R., Turakainen, M., Hartikainen, H. (2010): Plant availability of soil selenate additions and selenium distribution within wheat and ryegrass. - Plant Soil 333: 301-313.

[9] Kyodan, Y., Tetsuya, S., Munehim, Y. (1988): Identification of selenomethionine in soybean protein. - J. Agr. Food Chem. 36: 463-467.

[10] Leduc, D. L., Abdelsamie, M., Móntes-Bayon, M., Wu, C. P., Reisinger, S. J., Terry, N. (2006): Overexpressing both ATP sulfurylase and selenocysteine methyltransferase 
enhances selenium phytoremediation traits in Indian mustard. - Environ. Pollut. 144: 706.

[11] Li, Z., Man, N., Wang, S., Liang, D. L., Liu, J. J. (2015): Selenite adsorption and desorption in main Chinese soils with their characteristics and physicochemical properties. - J. Soil. Sediment. 15: 1150-1158.

[12] Liu, D., Li, H., Wang, Y., Ying, Z., Bian, Z., Zhu, W., Liu, W., Yang, L., Jiang, D. (2017): How exogenous selenium affects anthocyanin accumulation and biosynthesisrelated gene expression in purple lettuce. - Pol. J. Environ. Stud. 26: 717-722.

[13] Longchamp, M., Castrec-Rouelle, M., Biron, P. Bariac, T. (2015): Variations in the accumulation, localization and rate of metabolization of selenium in mature Zea mays plants supplied with selenite or selenite. - Food Chem. 182: 128-135.

[14] Matich, A. J., McKenzie, M. J., Lill, R. E., Brummell, D. A., McGhie, T. K., Chen, R. K. Y., Rowan, D. D. (2012): Selenoglucosinolates and their metabolites produced in Brassica spp. fertilised with sodium selenate. - Phytochemistry 75: 140-152.

[15] McCleod, S., (1975): Studies on wet oxidation procedures for the determination of organic carbon in soil. - In: Notes on Soil Techniques, pp. 73-79. CSIRO Division of Soils, Melbourne, Australia.

[16] McKenzie, M. J., Hunter, D. A., Pathirana, R., Watson, L. M., Joyce, N. I., Matich, A. J., Rowan, D. D., Brummell, D. A. (2009): Accumulation of an organic anticancer selenium compound in a transgenic Solanaceous species shows wider applicability of the selenocysteine methyltransferase transgene from selenium hyperaccumulators. Transgenic Res. 18: 407-424.

[17] Rayman, M. P., (2012): Selenium and human health. - Lancet 379: 1256-1268.

[18] Rayment, G. E., Higginson, F. R. (1992): Australian Laboratory Handbook of Soil and Water Chemical Methods. - Inkata Press, Melbourne, Australia.

[19] Renkema, H., Koopmans, A., Kersbergen, L., Kikkert, J., Hale, B., Berkelaar, E. (2011): The effect of transpiration on selenium uptake and mobility in durum wheat and spring canola. - Plant Soil 354: 239-250.

[20] Schiavon, M., Pilon-Smits, E. A. (2017): Selenium biofortification and phytoremediation phytotechnologies: a review. - J. Environ. Qual. 46: 10-19.

[21] Šindelářová, K., Száková, J., Tremlovã, J., Mestek, O., Praus, L., Kaňa, A., Najmanová, J., Tlustoš, P. (2015): The response of broccoli (Brassica oleracea convar. italica) varieties on foliar application of selenium: uptake, translocation, and speciation. - Food Addit Contam Part A Chem Anal Control Expo Risk Assess 32: 2027-2038.

[22] Song, Z., Shao, H., Huang, H., Shen, Y., Wang, L., Wu, F., Han, D., Song, J. Y. Jia, H. F. (2017): Overexpression of the phosphate transporter gene ospt8, improves the pi and selenium contents in Nicotiana tabacum. - Environ. Exp. Bot. 137: 158-165.

[23] Terry, N., Zayed, A. M., De Souza, M. P., Tarun, A. S. (2000): Selenium in higher plants. - Annu. Rev. Plant Physiol. Plant Mol. Biol. 51: 401-432.

[24] Wen, H. X., (2006): The influence of factors on selenium enrichment of mycelium of pleurotus ostreatus. - Food Science 27: 52-54.

[25] Wiesner-Reinhold, M., Schreiner, M., Baldermann, S., Schwarz, D., Hanschen, F. S., Kipp, A. P., Rowan, D. D., Bentley-Hewitt, K. L., McKenzie, M. J. (2017): Mechanisms of selenium enrichment and measurement in Brassicaceous vegetables, and their application to human health. - Front. Plant Sci. 8: 1365-1385.

[26] Xie, W. W. (2016): Comparative Study on Selenium Enriched Ability of Different Brassica Vegetables. - Southwest University, Chongqing, Beibei, China.

[27] Yawata, A., Oishi, Y., Anan, Y., Ogra, Y. (2010): Comparison of selenium metabolism in three Brassicaceae plants. - J. Health Sci. 56: 699-704.

[28] Zhang, M., Tang, S. H., Huang, X. (2014): Selenium uptake, dynamic changes in selenium content and its influence on photosynthesis and chlorophyll fluorescence in rice (Oryza sativa L.). - Environ. Exp. Bot. 107: 39-45. 
[29] Zhao, W. Y., Xu, W. H., Chai, Y. R., Zhou, X. B., Zhang, M. Z., Xie, W. W. (2017): Differences in selenium uptake, distribution, and expression of selenium metabolism genes in tomatoes. - Int. J. Agric. Biol. 19: 528-534.

[30] Zhou, X. B., Zhang, C. M., Wang, Y. K., Xu, W. H. (2016): Differences in selenium accumula in grains of two rice cultivars. - Bangl. J. Bot. 45: 811-818.

[31] Zhu, Y. G., Pilon-Smits, E. A., Zhao, F. J., Williams, P. N., Meharg, A. A. (2009): Selenium in higher plants: understanding mechanisms for biofortification and phytoremediation. - Trends Plant Sci. 14: 436-442. 